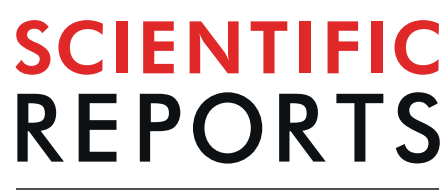

natureresearch

Check for updates

\title{
Hepatic steatosis among people living with HIV in Southern Brazil: prevalence and risk factors
}

\author{
Marina Ferri Pezzini ${ }^{1 凶}{ }^{\boxplus}$, Hugo Cheinquer ${ }^{2}$, Alexandre de Araujo ${ }^{3}$, Carlos T. Schmidt-Cerski ${ }^{4}$, \\ Eduardo Sprinz ${ }^{5}$, Fernando Herz-Wolff ${ }^{6}$ \&ulia Poeta ${ }^{7}$
}

Chronic liver disease is an important cause of morbidity and mortality among people living with human immunodeficiency virus (HIV) and is frequently related to non-alcoholic fatty liver disease (NAFLD). The objective is to estimate the prevalence and risk factors of hepatic steatosis among consecutive patients with stable HIV infection on antiretroviral therapy (ART). Also, the use of transient elastography (TE) as a mean to identify a subgroup at risk for non-alcoholic steatohepatitis (NASH) and/or liver fibrosis. HIV infected patients were enrolled between August2016 and February2017. Inclusion criteria: $\geq 18$ years with undetectable HIV viral load. Exclusion criteria: pregnancy; alcohol intake $\geq 20 \mathrm{~g} /$ day and co-infection $B$ or $C$ viruses. Patients underwent ultrasound (US) to diagnose liver steatosis. Significant fibrosis ( $\geq$ F2) was estimated if at least one of the following were present: APRI $>1.0$, FIB4 $>3$ and/ or liver stiffness $\geq 7.1 \mathrm{kPa}$. Subjects with $T E \geq 7.1 \mathrm{kPa}$ were proposed a liver biopsy and NAFLD Scoring System (NAS) $\geq 3$ was considered as diagnosis of NASH. A total of 98 patients were included. Liver steatosis was diagnosed in 31 patients (31.6\%) and was independently associated with male gender, BMI, ALT and total bilirubin levels. The prevalence of significant fibrosis assessed by TE, APRI and FIB4 was $26.9 \%, 6.4 \%$ and $3.2 \%$, respectively. Seven patients had a TE result $\geq 7.1 \mathrm{kPa}$. NASH was found in 5 (83.3\%). Among HIV infected patients undergoing ART, almost one third have NAFLD. Neither TE, APRI or FIB4 were able to act as surrogates for significant liver fibrosis. Nevertheless, TE $\geq 7.1 \mathrm{kPa}$ was able to accurately select a subgroup of patients at risk for NASH.

Human immunodeficiency virus (HIV) infection is a major public health problem worldwide and is rising in around 50 countries $^{1}$. Latest estimates from 2017 indicate that almost 36.9 million people are infected globally ${ }^{1}$, with around 1.8 million in Latin America ${ }^{2}$ and 860.000 in Brazil $^{3}$. Non-alcoholic fatty liver disease (NAFLD) is currently among one of the most common causes of liver disease, present in around $25 \%$ of individuals throughout the world ${ }^{4}$. Interestingly, the prevalence of NAFLD seems to be higher in people living with HIV compared to the general population, probably related to use of antiretroviral therapy (ART) and other prevalent factors such as obesity, dyslipidemia and/or metabolic syndrome ${ }^{5-11}$. NAFLD consists of a broad histopathological spectrum ranging from simple steatosis to nonalcoholic steatohepatitis (NASH), which could lead to cirrhosis and hepatocellular carcinoma ${ }^{12,13}$. Abdominal ultrasound (US) is the most common tool used to identify liver steatosis, however liver biopsy is still required to diagnose $\mathrm{NASH}^{14}$. Recently, some authors have advocated the use of serum biomarkers, combined or not with transient elastography (TE), to restrict indication of liver biopsy for patients at higher risk for $\mathrm{NASH}^{11,15-17}$. The aim of this study was to evaluate the prevalence and risk factors of hepatic steatosis among stable HIV infected patients undergoing ART. Moreover, use of TE was explored as a mean to identify a subgroup of individuals at risk for NASH and/or liver fibrosis to undergo liver biopsy.

${ }^{1}$ Post Graduate Program - Science in Gastroenterology and Hepatology, Hospital de Clínicas de Porto Alegre, Universidade Federal do Rio Grande do Sul, Porto Alegre, RS, Brazil. ²Gastroenterology and Hepatology Division; Hospital de Clínicas de Porto Alegre, Universidade Federal do Rio Grande do Sul, Porto Alegre, RS, Brazil. ${ }^{3}$ Gastroenterology and Hepatology Division, Hospital de Clínicas de Porto Alegre, Universidade Federal do Rio Grande do Sul, Porto Alegre, RS, Brazil. 'Pathology Division, Hospital de Clínicas de Porto Alegre, Universidade Federal do Rio Grande do Sul, Porto Alegre, RS, Brazil. ${ }^{5}$ Infectious Disease Service, Hospital de Clínicas de Porto Alegre, Universidade Federal do Rio Grande do Sul, Porto Alegre, RS, Brazil. ${ }^{6}$ Liver Disease Center, Hospital Moinhos de Vento, Universidade Federal do Rio Grande do Sul, Porto Alegre, RS, Brazil. ${ }^{7}$ Science Health Institute, Centro Universitário Ritter dos Reis, Universidade Federal do Rio Grande do Sul, Porto Alegre, RS, Brazil. ${ }^{凶}$-mail: mpezzini@hcpa.edu.br 


\section{Materials and methods}

Study population. Stable HIV infected patients undergoing ART were consecutively enrolled between August 2016 and February 2017 at the Human immunodeficiency virus /Acquired Immuno-Deficiency Syndrome (HIV/AIDS) outpatient clinic of Hospital de Clinicas de Porto Alegre (HCPA), a National reference center for HIV management in Southern Brazil. Patients $\geq 18$ years old with undetectable HIV viral load $(<50$ copies $/ \mathrm{mL}$ ) for at least 12 months were included. Exclusion criteria were the following: pregnancy; alcohol intake above $\geq 20 \mathrm{~g} /$ day and co-infection with hepatitis $\mathrm{B}$ or $\mathrm{C}$ viruses. All patients provided written informed consent. The Research Ethic Board of HCPA approved the study (study code 16-0312), which was conducted according to the Declaration of Helsinki.

Data collection. Data was prospectively collected by a single investigator using a standardized questionnaire with demographics, physical activity and alcohol consumption. Most recent laboratory results from the last 24 weeks were obtained from electronic medical records charts. Body mass index (BMI) was calculated as weight $(\mathrm{Kg}) /$ height $(\mathrm{m})^{2}$. HIV specific information was also obtained, such as time since diagnosis (years), duration of ART (years), most recent CD4 T-cell count (cells/ $\mu \mathrm{L})$, and current ART. The following data was also collected: impaired fasting glucose (IFG; defined as fasting blood glucose $\geq 100$ and $<126 \mathrm{mg} / \mathrm{dl}$, type 2 diabetes mellitus (DM2; defined as fasting blood glucose $\geq 126 \mathrm{mg} / \mathrm{dl}$ and/or treatment with oral antidiabetic drug/insulin) ${ }^{18}$, abnormal blood pressure (defined as blood pressure $\geq 130 / 85 \mathrm{mmHg}$ and/or treatment with anti-hypertensive drugs $)^{19}$, lipid profile including total cholesterol (TC), low density lipoprotein (LDL), high density lipoprotein (HDL) and triglycerides (TG); aspartate aminotransferase (AST), alanine aminotransferase (ALT) and total bilirubin (TB). Metabolic syndrome was defined according to National Cholesterol Education Program Adult Treatment Panel III (ATP-III) as the presence of three or more of the following: blood pressure $\geq 130 / 85 \mathrm{mmHg}$; fasting plasma glucose $\geq 110 \mathrm{mg} / \mathrm{dL}$; waist circumference $>102 \mathrm{~cm}$ for men or $>88 \mathrm{~cm}$ for women; HDL cholesterol $<40 \mathrm{mg} / \mathrm{dL}$ for men or $<50 \mathrm{mg} / \mathrm{dL}$ for women; and $\mathrm{TG} \geq 150 \mathrm{mg} / \mathrm{dL}^{20}$.

Steatosis and fibrosis assessment. All patients underwent abdominal US with an experienced radiologist. Liver steatosis was diagnosed according to previously established criteria ${ }^{21}$. The following non-invasive fibrosis markers were calculated: AST to Platelet Ratio Index (APRI) as [AST (IU/L)/AST upper limit of normal $(\mathrm{IU} / \mathrm{L}) /$ Platelets $\left.\left(10^{9} / \mathrm{L}\right) \times 100\right]^{22}$ and FIB4 score as [age $($ years $) \times$ AST $\left.(\mathrm{IU} / \mathrm{L})\right] /\left[\text { Platelets }\left(10^{9} / \mathrm{L}\right) \times \text { ALT }(\mathrm{IU} / \mathrm{L})\right]^{23}$. Cut off values used for significant fibrosis (Metavir $\geq$ F2) were APRI $>1.0$ and FIB-4 $>3.0$. Transient elastography was performed by an experienced investigator after at least 4 hours of fasting using FibroScan ${ }^{\circledR}$ (Echosens; Paris, France). The standard M probe was used in all except three patients that required the XL probe due to BMI $\geq 30$ $\mathrm{Kg} / \mathrm{m}^{2}$. A liver stiffness result was considered reliable if the interquartile range (IQR) was $<30 \%$ and the success rate was $\geq 70 \%$. Significant fibrosis (Metavir $\geq$ F2) was estimated using a liver stiffness result cut-off $\geq 7.1 \mathrm{kPa}^{7,13}$. Steatosis was estimated using a controlled attenuation parameter (CAP) cut-off $\geq 238 \mathrm{~dB} / \mathrm{m}^{7,11}$. Subjects with $\mathrm{TE} \geq 7.1 \mathrm{kPa}$ were proposed a liver biopsy. Histological evaluation was performed by an expert liver pathologist using the NAFLD Scoring System (NAS), which is a result of the unweighted sum of scores of steatosis (0-3), lobular inflammation ( $0-3$ ), and hepatocellular ballooning (0-2) ranging between $0-8$. A calculated NAS $\geq 3$ was considered as diagnosis of $\mathrm{NASH}^{24}$.

Statistical analysis. Statistical tests were performed using The Statistical Package for Social Science version 18.0 (SPSS, Chicago, IL). Continuous variables were expressed as median (IQR), and categorical variables were presented as numbers (percentage). Mann-Whitney's U test was applied for comparisons of continuous variables between groups. Comparisons between categorical variables were made by the chi-square test or Fisher's exact test, when appropriate. Poisson regression model was used to identify factors associated with hepatic steatosis and to detect any potential confounders. This model was chosen since it is the most accurate in estimating the prevalence ratio (PR) in cross sectional studies ${ }^{25}$. Only variables with a $p \leq 0.10$ at univariate analysis were entered in the multivariate model. Associations with a $p \leq 0.05$ were considered statistically significant.

\section{Results}

A total of $98 \mathrm{HIV}$ infected patients were included. Mean age was $49 \pm 11$ years and 53 (54.1\%) were male. Patients characteristics such as demographics, comorbidities and laboratory results are summarized in Table 1. Fatty liver was detected by ultrasound in 31/98 (31.6\%). The most common ART regimen used was Tenofovir (TDF) + Lamivudine (3TC) + Efavirenz (EFV) in $23.4 \%$ of the patients, followed by Zidovudine $(\mathrm{ZDV})+3 \mathrm{TC}+\mathrm{EFV}$ in $20.4 \%$. Triglyceride levels $\geq 150 \mathrm{mg} / \mathrm{dL}$ were detected in $54(55.1 \%)$ patients, total cholesterol levels $\geq 200 \mathrm{mg} / \mathrm{dL}$ in 36 (36.7\%), and ALT above the upper limit of normal (ULN) in 23 (23.5\%). In univariate analysis, fatty liver was associated with male gender, BMI, IFG/diabetes, metabolic syndrome, triglycerides, LDL, total bilirubin and ALT levels, and non-invasive fibrosis scores (APRI and FIB-4). In multivariate analysis fatty liver was independently associated with male gender, BMI, triglycerides, total bilirubin and ALT levels (Tables 2 and 3).

Among the 31 patients with hepatic steatosis, prevalence of significant fibrosis (Metavir $\geq$ F2) assessed by serum biomarkers (APRI and FIB-4) was $6.4 \%$ and 3.2\%, respectively. Transient elastography was performed in 26 of the 31 patients with hepatic steatosis, while five patients refused the procedure. Significant fibrosis (Metavir $\geq$ F2) assessed by TE was found in 7 (26.9\%) patients and was associated with triglyceride levels, FIB-4 score and CAP values (Table 4). Six of these patients agreed to undergo a liver biopsy, which was found compatible with NASH in $5(83.3 \%)$ and with mild liver fibrosis without NASH in one. No biopsied patient had significant fibrosis (Table 5). 


\begin{tabular}{|c|c|}
\hline Characteristics & Value \\
\hline \multicolumn{2}{|l|}{ Demographics } \\
\hline Age (years) & $49 \pm 11$ \\
\hline Gender, male (\%) & $53(54.1 \%)$ \\
\hline Ethnicity, white & $84(85.7 \%)$ \\
\hline $\mathrm{BMI}\left(\mathrm{Kg} / \mathrm{m}^{2}\right)$ & $25.45(23.6-28.2)$ \\
\hline Physical activity* & $18(18.4 \%)$ \\
\hline \multicolumn{2}{|l|}{ Comorbidities } \\
\hline Hypertension (\%) & $27(27.6 \%)$ \\
\hline IFG/Diabetes (\%) & $35(35.7 \%)$ \\
\hline Metabolic syndrome (\%) & $31(31.6 \%)$ \\
\hline Dyslipidemia & $79(80.6 \%)$ \\
\hline \multicolumn{2}{|l|}{ Laboratory } \\
\hline Triglycerides (mg/dl) & $156(118-2-8)$ \\
\hline Total cholesterol (mg/dl) & $188.6 \pm 34$ \\
\hline Low density lipoprotein cholesterol (mg/dl) & $103.3 \pm 30$ \\
\hline High density lipoprotein cholesterol (mg/dl) & $45.50(38-55)$ \\
\hline Aspartate aminotransferase (U/L) & $21(17-26)$ \\
\hline Alanine aminotransferase (U/L) & $22(16-30)$ \\
\hline Total bilirubin & $0.4(0.3-1.2)$ \\
\hline \multicolumn{2}{|l|}{ HIV } \\
\hline Time since HIV (years) & $15(6-20)$ \\
\hline Time on ART (years) & $11(5-16)$ \\
\hline CD4 count (cells/ $\mu \mathrm{L})$ & $657.5(118-208)$ \\
\hline
\end{tabular}

Table 1. Characteristics of the study population $(n=98)$. Data were expressed as number $(\%)$, mean \pm standard deviation (SD) for quantitative variables with normal distribution, or median (IQR) for quantitative variables without normal distribution. Abbreviations: BMI, body mass index; IGF, impaired fasting glucose; ART, antiretroviral therapy. *Physical activity was considered above 3 times a week.

\begin{tabular}{|c|c|c|c|c|c|c|}
\hline Characteristics & $\begin{array}{l}\text { No steatosis } \\
n=67\end{array}$ & Steatosis $\mathbf{n}=\mathbf{3 1}$ & $\begin{array}{l}\mathrm{PR}(95 \% \mathrm{Cl})^{\mathrm{a}} \\
\text { Unadjusted }\end{array}$ & P univariate & $\begin{array}{l}\text { Adjusted PR } \\
(95 \% \mathrm{Cl})^{\mathrm{a}}\end{array}$ & P multivariate \\
\hline \multicolumn{7}{|l|}{ Demographics } \\
\hline Age (years) & $48 \pm 12$ & $51 \pm 10$ & $1.02(0.99-1.04)$ & 0.146 & & \\
\hline Gender, male (\%) & $31(46.3)$ & $22(71.0)$ & $2.07(1.07-4.04)$ & 0.032 & $2.99(1.15-8.45)$ & 0.030 \\
\hline $\operatorname{BMI}\left(\mathrm{Kg} / \mathrm{m}^{2}\right)^{*}$ & $25.2(23-27.8)$ & $26.8(24.9-29.6)$ & $1.08(1.03-1.13)$ & 0.006 & $1.13(1.02-1.30)$ & 0.032 \\
\hline Hypertension (\%) & $19(28.4)$ & $8(25.8)$ & $0.91(0.47-1.79)$ & 0.795 & & \\
\hline IFG/Diabetes (\%) & $19(28.4)$ & $16(51.6)$ & $1.92(1.08-3.40)$ & 0.025 & $2.21(0.79-6.24)$ & 0.130 \\
\hline MS (\%) & $17(25.4)$ & $14(45.2)$ & $1.64(0.93-2.90)$ & 0.090 & $1.20(0.40-3.50)$ & 0.778 \\
\hline \multicolumn{7}{|l|}{ HIV } \\
\hline Time since HIV (years)* & $14(4-2)$ & $16(9-20)$ & $1.02(0.98-1.06)$ & 0.310 & & \\
\hline Time on ART (years)* & $9(3-17)$ & $13(7-16)$ & $1.03(0.99-1.07)$ & 0.128 & & \\
\hline CD 4 count $(\text { cells } / \mu \mathrm{L})^{*}$ & $680(539-864)$ & $607(538-828)$ & $1.00(1.00-1.01)$ & 0.484 & & \\
\hline
\end{tabular}

Table 2. Variables associated with presence/absence of liver steatosis in HIV monoinfected patients. Abbreviations: BMI, body mass index; IFG, impaired fasting glucose; MS, metabolic syndrome; ART, antiretroviral therapy; PR, prevalence ration; CI, confidence interval. Median (IQR)*. ${ }^{\text {aPrevalence ratio and }}$ confidence intervals were estimated using Poisson regression.

\section{Discussion}

The present study investigated the prevalence and associated risk factors for liver steatosis among stable HIV infected outpatients in a tertiary care center in Southern Brazil. Furthermore, we explored the role of TE to identify a subgroup of patients at risk for NASH and/or liver fibrosis among this population. Using abdominal US, hepatic steatosis was detected in almost a third of our sample. This finding is similar to the prevalence reported in a recent systematic review and meta-analysis conducted among HIV monoinfected patients from several countries worldwide, which found NAFLD using mainly US imaging in 35.3\% (95\% CI 28.8-42.5) ${ }^{26}$. This prevalence seems to be at least $10 \%$ higher than what has been usually reported in the general population. Indeed, a recent meta-analytic assessment of the global NAFLD epidemiology among a large group of unselected individuals detected liver steatosis in only $25.2 \%$ (95\% CI 22.1-28.6) ${ }^{4}$. Nevertheless, one could assume that the true prevalence of NAFLD is probably higher, since abdominal US is known to detect liver steatosis only when more than $20-30 \%$ of hepatocytes are affected ${ }^{23}$. In our study, hepatic steatosis was independently associated with male 


\begin{tabular}{|c|c|c|c|c|c|c|}
\hline Characteristics & No steatosis $n=67$ & Steatosis $n=31$ & $\begin{array}{l}\text { Unadjusted PR } \\
(95 \% \mathrm{Cl})^{\mathrm{a}}\end{array}$ & P univariate & $\begin{array}{l}\text { Adjusted PR } \\
(95 \% \mathrm{Cl})^{\mathrm{a}}\end{array}$ & P multivariate \\
\hline \multicolumn{7}{|l|}{ Labs } \\
\hline Triglycerides $(\mathrm{mg} / \mathrm{dL})^{*}$ & $148(102-188)$ & $199(147-243)$ & $1.00(1.00-1.01)$ & $<0.001$ & $1.00(1.00-1.01)$ & 0.012 \\
\hline Total cholesterol (mg/dL) & $189 \pm 33$ & $187 \pm 38$ & $1.00(0.90-1.01)$ & 0.709 & & \\
\hline LDL cholesterol (mg/dL) & $107 \pm 31$ & $96 \pm 30$ & $1.00(0.98-1.00)$ & 0.083 & & \\
\hline HDL cholesterol $(\mathrm{mg} / \mathrm{dL})^{*}$ & $46(40-60)$ & $42(35-53)$ & $0.99(0.95-1.02)$ & 0.352 & & \\
\hline $\operatorname{AST}(\mathrm{U} / \mathrm{L})^{*}$ & $21(17-24)$ & $23(20-29)$ & $1.01(0.99-1.04)$ & 0.190 & & \\
\hline $\operatorname{ALT}(\mathrm{U} / \mathrm{L})^{*}$ & $22(15-27)$ & $28(19-42)$ & $1.02(1.01-1.03)$ & $<0.001$ & $1.15(1.07-1.23)$ & 0.003 \\
\hline Total bilirubin $(\mathrm{mg} / \mathrm{dL})^{*}$ & $0.3(0.3-0.6)$ & $0.7(0.4-2.1)$ & $1.24(1.02-1.50)$ & 0.027 & $2.02(1.25-3.45)$ & 0.006 \\
\hline \multicolumn{7}{|l|}{ Fibrosis markers } \\
\hline FIB-4 score* & $0.860(0.630-1.220)$ & $0.910(0.760-1.460)$ & $1.33(1.08-1.64)$ & 0.007 & & \\
\hline APRI score* & $0.197(0.154-0.306)$ & $0.256(0.198-1.385)$ & $3.42(1.53-7.64)$ & 0.003 & & \\
\hline
\end{tabular}

Table 3. Variables associated with presence/absence of liver steatosis in HIV monoinfected patients. Median

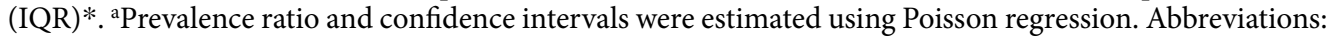
LDL, low density protein; HDL, high density protein; AST, aspartate aminotransferase; ALT, alanine aminotransferase; FIB-4, fibrosis-4; APRI, AST to platelet ratio index; PR, prevalence ratio; CI, confidence interval.

\begin{tabular}{|c|c|c|c|c|}
\hline Characteristics & $\mathrm{TE} \geq 7.1 \mathrm{kPa} \mathrm{n}=7$ & $\mathrm{TE}<7.1 \mathrm{kPa} \mathrm{n}=19$ & \multicolumn{2}{|c|}{ Unadjusted $P$ PR $(95 \% \mathrm{Cl})^{\mathrm{a}}$ univariate } \\
\hline \multicolumn{5}{|l|}{ Demographics } \\
\hline Age (years) & $50 \pm 6$ & $51 \pm 12$ & $0.99(0.94-1.04)$ & 0.694 \\
\hline Sex, male (\%) & $5(71.4)$ & $14(73.7)$ & $0.92(0.23-3.80)$ & 0.908 \\
\hline $\operatorname{BMI}\left(\mathrm{Kg} / \mathrm{m}^{2}\right)^{*}$ & $27.4(24.4-32.5)$ & $26.8(24.7-29.3)$ & $1.07(0.95-1.19)$ & 0.273 \\
\hline Physical activity $\left.{ }^{\S} \%\right)$ & $4(57.1)$ & $4(21.1)$ & $3.00(0.86-10.4)$ & 0.083 \\
\hline Hypertension (\%) & $2(28.6)$ & $2(10.5)$ & $2.20(0.63-7.65)$ & 0.215 \\
\hline IFG/Diabetes (\%) & $4(57.1)$ & $9(47.4)$ & $1.33(0.37-4.82)$ & 0.661 \\
\hline Metabolic syndrome (\%) & $5(71.4)$ & $5(26.3)$ & $4.00(0.95-16.8)$ & 0.059 \\
\hline \multicolumn{5}{|l|}{ HIV } \\
\hline Time since HIV (years)* & $20(9-22)$ & $16(6-21)$ & $1.05(0.95-1.17)$ & 0.353 \\
\hline Time on ART (years)* & $14(7-22)$ & $14(6-16)$ & $1.05(0.95-1.15)$ & 0.367 \\
\hline CD4 count $(\text { cells } / \mu \mathrm{L})^{*}$ & $698(541-828)$ & $607(450-879)$ & $1.00(1.00-1.00)$ & 0.499 \\
\hline \multicolumn{5}{|l|}{ Labs } \\
\hline Triglycerides $(\mathrm{mg} / \mathrm{dL})^{*}$ & $240(219-438)$ & $175(125-228)$ & $1.00(1.00-1.10)$ & 0.037 \\
\hline Total cholesterol (mg/dL) & $190 \pm 36$ & $185 \pm 36$ & $1.00(1.00-1.02)$ & 0.773 \\
\hline LDL cholesterol (mg/dL) & $88 \pm 27$ & $100 \pm 26$ & $0.99(0.96-1.01)$ & 0.328 \\
\hline HDL cholesterol $(\mathrm{mg} / \mathrm{dL})^{*}$ & $36(31-53)$ & $45(37-51)$ & $0.97(1.00-1.05)$ & 0.481 \\
\hline $\operatorname{AST}(\mathrm{U} / \mathrm{L}) *$ & $26(20-35)$ & $24(21-29)$ & $1.02(0.95-1.10)$ & 0.566 \\
\hline $\operatorname{ALT}(\mathrm{U} / \mathrm{L})^{*}$ & $44(28-73)$ & $27(20-40)$ & $1.01(0.99-1.04)$ & 0.302 \\
\hline Total bilirubin $(\mathrm{mg} / \mathrm{dL})^{*}$ & $0.7(0.4-2.2)$ & $0.7(0.3-2.5)$ & $0.98(0.56-1.60)$ & 0.938 \\
\hline \multicolumn{5}{|l|}{ Noninvasive markers } \\
\hline APRI score* & $0.255(0.149-0.447)$ & $0.274(0.201-0.401)$ & $1.45(0.15-14.34)$ & 0.752 \\
\hline FIB4 score* & $0.98(0.66-2.64)$ & $0.90(0.76-1.0)$ & $1.46(1.15-1.86)$ & 0.002 \\
\hline \multicolumn{5}{|l|}{ Transient elastography } \\
\hline CAP* & $360(320-364)$ & $272(246-294)$ & $1.02(1.00-1.04)$ & 0.049 \\
\hline $\mathrm{CAP} \geq 238(\mathrm{~dB} / \mathrm{m})(\%)$ & $4(57.1)$ & $16(84.2)$ & $0.60(1.00-3.72)$ & 0.583 \\
\hline
\end{tabular}

Table 4. Variables associated with $\mathrm{TE} \geq 7.1 \mathrm{kPa} / \mathrm{TE}<7.1 \mathrm{kPa}$ in $\mathrm{HIV}$ monoinfected patients. Abbreviations: TE, transient elastography; BMI, body mass index; IFG, impaired fasting glucose; ART, antiretroviral therapy; LDL, low density lipoprotein; HDL, high density lipoprotein; AST, aspartate aminotransferase; ALT, alanine aminotransferase; FIB-4, fibrosis-4; APRI, AST to platelet ratio index; CAP, controlled attenuation parameter; $\mathrm{PR}$, prevalence ration; CI, confidence interval. Median (IQR)*. ${ }^{5} \mathrm{Physical}$ activity was considered above 3 times a week. ${ }^{a}$ Prevalence ratio and confidence intervals were estimated using Poisson regression.

gender and BMI, as well as TG, ALT and TB levels. Similar results were reported by several other authors ${ }^{7,8,11,13,22}$. Noteworthy, our study did not show an association between NAFLD and HIV parameters such as duration of infection, duration of ART and CD4 cell count. Same results were reported in other studies ${ }^{8,11}$. 


\begin{tabular}{|c|c|c|c|c|c|c|}
\hline Characteristics & Case 1 & Case 2 & Case 3 & Case 4 & Case 5 & Case 6 \\
\hline \multicolumn{7}{|l|}{ Demographics } \\
\hline Age/gender & $43 / \mathrm{male}$ & $44 / \mathrm{male}$ & $54 / \mathrm{male}$ & $58 / \mathrm{male}$ & $44 / \mathrm{male}$ & $57 /$ female \\
\hline \multicolumn{7}{|l|}{ Non invasive markers } \\
\hline APRI score & 0.326 & 1.013 & 0.447 & 0.255 & 0.243 & 0.15 \\
\hline FIB4 score & 0.66 & 2.64 & 1.46 & 0.85 & 0.63 & 0.98 \\
\hline \multicolumn{7}{|l|}{ TE parameters } \\
\hline Liver stiffness $(\mathrm{kPa})$ & 8.6 & 9.9 & 7.6 & 12 & 7.9 & 9.1 \\
\hline CAP & 364 & 320 & 360 & - & 231 & 375 \\
\hline \multicolumn{7}{|l|}{ Biopsy } \\
\hline Fragment size $(\mathrm{mm})$ & $1.6 \times 0.1 \times 0.1$ & $1.5 \times 0.1 \times 0.1$ & $1.7 \times 0.1 \times 0.1$ & $1.6 \times 0.1 \times 0.1$ & $1.3 \times 0.1 \times 0.1$ & $1.6 \times 0.1 \times 0.1$ \\
\hline Histologic diagnosis & $\begin{array}{l}\text { NASH } \\
\text { Fibrosis F0 }\end{array}$ & $\begin{array}{l}\text { Without } \\
\text { NASH } \\
\text { Fibrosis F1 }\end{array}$ & $\begin{array}{l}\text { NASH } \\
\text { Fibrosis F0 }\end{array}$ & $\begin{array}{l}\text { NASH } \\
\text { Fibrosis F0 }\end{array}$ & $\begin{array}{l}\text { NASH } \\
\text { Fibrosis F1 }\end{array}$ & $\begin{array}{l}\text { NASH } \\
\text { Fibrosis F1 }\end{array}$ \\
\hline
\end{tabular}

Table 5. Clinical characteristics of HIV patients with liver steatosis and TE $\geq 7.1 \mathrm{kPa}$ underwent liver biopsy. Abbreviations: FIB-4, fibrosis-4; APRI, AST to platelet ratio index; CAP, controlled attenuation parameter; $\mathrm{NASH}$, nonalcoholic steatohepatitis.

Among our group of 26 patients with steatosis that underwent TE, 7 (26.9\%) had liver stiffness above $7.1 \mathrm{kPa}$. This result is comparable with that found by other authors that used TE cut-offs between 7.0 and $7.4 \mathrm{kPa}$ as a surrogate for significant fibrosis among HIV infected patients, and found $15 \%$ to $27.3 \%$ individuals within that range ${ }^{5,7,23}$. Remarkably, none of our six patients with liver stiffness above $7.1 \mathrm{kPa}$ that underwent liver biopsy had significant fibrosis. This finding suggests that TE may overestimate fibrosis staging in HIV patients with hepatic steatosis detected by US. On the other hand, all except one of our biopsied patients had NASH, indicating that TE was capable of identifying a subgroup at risk for this condition among HIV patients with liver steatosis. Future studies could explore different cut-off values for TE in this population in order to improve its usefulness as a tool to detect not only NASH, but also significant fibrosis.

Interestingly, there was discordance in our sample between TE and APRI and FIB-4. Indeed, the majority of the patients with TE $\geq 7.1 \mathrm{kPa}$ had normal FIB-4 and APRI values. This observation was also reported by other authors and highlights the difficulty of assessing correctly the liver fibrosis staging in this population without the use of an invasive method such as a liver biopsy $y^{5,22}$.

Our study has some limitations: it is a cross sectional study, so it was not possible to define the consecutive steps leading to the development of both steatosis and fibrosis in HIV infected patients; only a few of the NAFLD patients agreed to undergo liver biopsy, so we cannot rule out the occurrence of NASH and/or significant fibrosis among the remaining patients that refused the procedure; NAFLD fibrosis score (NFS) was not calculated due to the fact that some variables used for its calculation were not routinely collected for most of the patients that comprised this cohort. Finally, the small sample size among subjects submitted to TE prevented us to further explore multivariate analysis in this subgroup of patients.

In conclusion, it is important to realize that TE using a cut-off of $7.1 \mathrm{kPa}$ was able to accurately detect patients with high risk for NASH among HIV monoinfected individuals with NAFLD. The significance of this finding should be validated in larger cohorts, preferably with long term follow-up. If the ability of TE to correctly identify $\mathrm{NASH}$ in this population is confirmed, invasive procedures such as liver biopsy could be reserved for identification of significant fibrosis, since TE was not accurate enough to identify this condition. Further studies should explore different TE cut-offs and/or combinations of non-invasive methods to better select patients at risk for significant fibrosis, because this individuals are the ones at higher risk for progressive liver disease and are the best candidates for more aggressive medical management to avoid deleterious outcomes.

Received: 5 December 2019; Accepted: 16 April 2020;

Published online: 19 May 2020

\section{References}

1. UNAIDS- Global HIV and AIDS statistics- 2018 fact sheet. [Cited in 2018 Oct 25] Available from, http://www.unaids.org/en/ resources/fact-sheet.

2. UNAIDS- DATA 2018 [Cited in 2018 Oct 25] Available from, http://www.unaids.org/sites/default/files/media_asset/unaidsdata-2018_en.pdf.

3. http://www.unaids.org/en/regionscountries/countries/brazil.

4. Younossi, Z. M. et al. Global epidemiology of nonalcoholic fatty liver disease-Meta-analytic assessment of prevalence, incidence, and outcomes. Hepatology. 64, 73-84 (2016).

5. Lui, G. et al. Liver fibrosis and fatty liver in Asian HIV-infected patients. Aliment Pharmacol Ther 44, 411-421 (2016).

6. Croxford, S. et al. Mortality and causes of death in people diagnosed with HIV in the era of highly active antiretroviral therapy compared with the general population: an analysis of a national observational cohort. Lancet Public Health 2(1), e35-e46 (2017).

7. Vuille-Lessard, É. et al. Nonalcoholic fatty liver disease diagnosed by transient elastography with controlled attenuation parameter in unselected HIV monoinfected patients. Aids. 30, 2635-2643 (2016).

8. Nishijima, T. et al. Traditional but not HIV-related factors are associated with nonalcoholic fatty liver disease in asian patients with HIV-1 infection. PLoS One. 9, 1-6 (2014).

69. Sulyok, M. et al. Hepatic steatosis in individuals living with HIV measured by controlled attenuation parameter: A cross-sectional study. Eur J Gastroenterol Hepatol 27, 679-685 (2015). 
10. Rockstroh, J. K., Mohr, R., Behrens, G. \& Spengler, U. Liver fibrosis in HIV: Which role does HIV itself, long-term drug toxicities and metabolic changes play? Curr Opin HIV AIDS 9, 365-370 (2014).

11. Macías, J. et al. Prevalence and factors associated with liver steatosis as measured by transient elastography with controlled attenuation parameter in HIV-infected patients. Aids. 28, 1279-1287 (2014).

12. Rivero-Juárez, A. et al. Incidence of Liver Damage of Uncertain Origin in HIV Patients Not Co-Infected with HCV/HBV. PLoS One. 8,7-12 (2013).

13. Pembroke, T. et al. Hepatic steatosis progresses faster in HIV mono-infected than HIV/HCV co-infected patients and is associated with liver fibrosis. J Hepatol. 67, 801-808 (2017).

14. Rockey, D. C., Caldwell, S. H., Goodman, Z. D., Nelson, R. C. \& Smith, A. D. Liver biopsy. Hepatology 49, 1017-1044 (2009).

15. Schmid, P. et al. Progression of liver fibrosis in HIV/HCV co-infection: A comparison between non-invasive assessment methods and liver biopsy. PLoS One. 10, 1-18 (2015).

16. Macías, J. et al. Changes in liver steatosis evaluated by transient elastography with the controlled attenuation parameter in HIVinfected patients. HIV Med. 17, 766-773 (2016).

17. Chalasani, N. et al. The diagnosis and management of nonalcoholic fatty liver disease: Practice guidance from the American Association for the Study of Liver Diseases. Hepatology. 67, 328-357 (2018).

18. Professional Practice Committee: Standards of Medical Care in Diabetes-2018. Diabetes Care 2018; 41:S3-S3. [cited 2018 nov 7]. Available from, https://diabetesed.net/wp-content/uploads/2017/12/2018-ADA-Standards-of-Care.pdf.

19. Whelton, P. K. et al. ACC/AHA/AAPA/ABC/ACPM/AGS/APhA/ASH/ASPC/NMA/PCNA Guideline for the Prevention, Detection, Evaluation, and Management of High Blood Pressure in Adults: A Report of the American College of Cardiology/American Heart Association Task Force on Clinical Pr. J Am Coll Cardiol. 71 (e127-e248 (2018).

20. Rezaianzadeh, A., Namayandeh, S. M. \& Sadr, S. M. National Cholesterol Education Program Adult Treatment Panel III Versus International Diabetic Federation Definition of Metabolic Syndrome, Which One is Associated with Diabetes Mellitus and Coronary Artery Disease? Int J Prev Med 3(8), 552-558 (2012).

21. Lee, S. S. \& Park, S. H. Radiologic evaluation of nonalcoholic fatty liver disease. World J Gastroenterol 20, 7392-7402 (2014).

22. Lombardi, R. et al. Prevalence and predictors of liver steatosis and fibrosis in unselected patients with HIV mono-infection. Dig Liver Dis 48, 1471-1477 (2016).

23. Lombardi, R. et al. Liver test abnormalities in patients with HIV mono-infection: Assessment with simple noninvasive fibrosis markers. Ann Gastroenterol 30, 349-356 (2017).

24. Kleiner, D. E. et al. Design and validation of a histological scoring system for nonalcoholic fatty liver disease. Hepatology. 41(6), 1313-1321 (2005).

25. Barros, A. J. D. \& Hirakata, V. N. Alternatives for logistic regression in crosssectional studies: An empirical comparison of models that directly estimate the prevalence ratio. BMC Med Res Methodol 3, 21 (2003).

26. Maurice, J. B. et al. Prevalence and risk factors of nonalcoholic fatty liver disease in HIVmonoinfection. A systemic Review and Meta-Analysis. AIDS. 31(11), 1621-1632 (2017).

\section{Acknowledgements}

The authors would like to acknowledge the patients, their families and all team of Hospital de Clinicas de Porto Alegre that contributed with this study.

\section{Author contributions}

M.F.P: literature review, research project, interview with individuals, data collect, statistical analysis, paper elaboration, paper submission. H.C.: elastography, paper elaboration. A.A., C.C., T.C., F.W. and J.P.: data collect, paper elaboration. E.S.: literature review, research project.

\section{Competing interests}

The authors declare no competing interests.

\section{Additional information}

Correspondence and requests for materials should be addressed to M.F.P.

Reprints and permissions information is available at www.nature.com/reprints.

Publisher's note Springer Nature remains neutral with regard to jurisdictional claims in published maps and institutional affiliations.

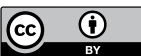

Open Access This article is licensed under a Creative Commons Attribution 4.0 International License, which permits use, sharing, adaptation, distribution and reproduction in any medium or format, as long as you give appropriate credit to the original author(s) and the source, provide a link to the Creative Commons license, and indicate if changes were made. The images or other third party material in this article are included in the article's Creative Commons license, unless indicated otherwise in a credit line to the material. If material is not included in the article's Creative Commons license and your intended use is not permitted by statutory regulation or exceeds the permitted use, you will need to obtain permission directly from the copyright holder. To view a copy of this license, visit http://creativecommons.org/licenses/by/4.0/.

(C) The Author(s) 2020 